\title{
АКТУАЛЬНЫЕ ПРОБЛЕМЫ ПРОВЕДЕНИЯ СТРОИТЕЛЬНОЙ ЭКСПЕРТИЗЫ В РОССИИ
}

\section{(c) 2020 Костылев Петр Николаевич}

студент кафедры проектирования зданий и экспертизы недвижимости

Сибирский федеральный университет, Россия, Красноярск

E-mail: qpeterkosq@gmail.com

\section{(C) 2020 Амзаракова Полина Александровна}

студент кафедры проектирования зданий и экспертизы недвижимости

Сибирский федеральный университет, Россия, Красноярск

E-mail:pol.amzarakova@yandex.ru

\section{(c) 2020 Аглямзянов Эмиль Ринатович}

студент кафедры проектирования зданий и экспертизы недвижимости

Сибирский федеральный университет, Россия, Красноярск

E-mail: emildzy3@yandex.ru

\section{(c) 2020 Толочко Ольга Романовна}

студент магистратуры кафедры проектирования зданий и экспертизы недвижимости

Сибирский федеральный университет, Россия, Красноярск

E-mail: 89131804624@mail.ru

\section{(c) 2020 Азахов Эльвин Тахирович}

выпускник отделения промышленного и гражданского строительства инженерно-строительного института

Сибирский федеральный университет, Россия, Красноярск

E-mail: el.azakhov98@gmail.com

В статье выполнен анализ экспертной сферы в России, рассмотрены проблемы, которые связаны с проведением строительной экспертизы. Было доказано, что данная тема актуальна, в связи с тем, что отрасль строительства в Российской Федерации развивается, и за последние годы наблюдается положительная динамика роста. Рассмотрены основные понятия, связанные с экспертизой, а также приведена ее классификация по различным признакам.

Ключевые слова: экспертиза, строительная экспертиза, строительство, классификация экспертиз, судебная экспертиза, несудебная экспертиза.

Одной из развивающихся сфер экономики Российской Федерации является строительство. По данным Федеральной службы государственной статистики ввод в действие жилых домов на территории страны имеет положительную тенденцию (рисунок 1). Что в свою очередь свидетельствует об увеличении объемов строительства и росте количества участников строительного производства [1].

За последние десятилетия развития строительной отрасли в Российской Федерации в нее были внесены многие изменения касательно сферы строительной экспертизы. Одним из основных характерных показателей современного состояния строительства в Российской Феде- рации является растущее количество правонарушений, происходящих между участниками строительства, в число которых входят производители и поставщики строительных материалов, строительные и страховые компании, банки, органы власти, инвесторы, акционеры, дольщики и т.д. Такой многочисленный и разнообразный состав вовлеченных лиц неизбежно приводит к конфликтам, которые возможно решить лишь в судебном порядке.

С целью разрешения конфликта между заказчиком и подрядчиком, субъекты обращаются к третьей независимой стороне, в роли которой выступает экспертная организация. Подобная организация может быть как государственной, 


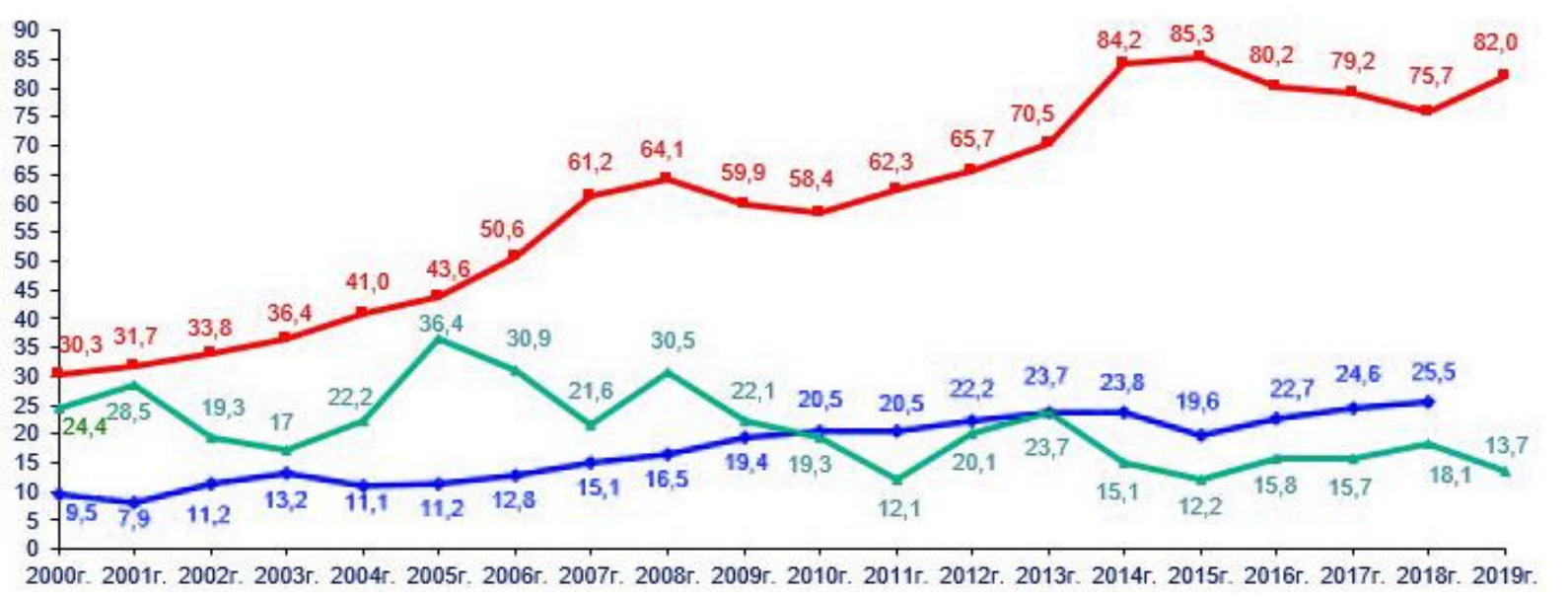

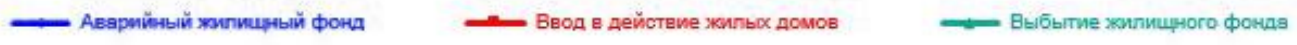

Рисунок 1. Движение жилищного фонда, млн. $\mathbf{m}^{2}$

так и негосударственной.

На сегодняшний день выделяют разновидности экспертиз согласно следующим показателям:

1) согласно дисциплине исследования (тип специальных знаний, необходимых для проведения экспертизы);

2) согласно полноте заключения эксперта;

3) согласно числу участников, которые проводят экспертные работы;

4) согласно правовому статусу.

Далее проанализируем разновидности более подробней. По первому признаку экспертизы могут быть криминалистическими, медицинскими, инженерными (технические, технологические), экономические и.т.д. Строительная экспертиза принадлежит инженерному виду.

В заключении эксперта должны быть отображены аргументированные и исчерпывающие тезисы. Специалист должен решить все возникшие проблемы и вопросы. В ситуации, когда какой-либо пункт экспертизы останется без внимания эксперта, специалист должен аргументировать причину этого в заключении. В соответствие с этим критерием экспертиза делиться на первичную и вторичную.

Первичная отличается от вторичной тем, что ее проводят по определенному судебному делу первый раз, в отличие от вторичной экспертизы, которая назначается в случае выявления недостаточной проработки в процессе первичных экспертных работ.

Дополнительная назначается в случае необходимости пояснений после проведения первичной экспертизы. Особенность этого вида экспертных работ в том, что их проведение не требует исследования в полном объеме, а только тех положений, в которых были выявлены недостатки.

Причиной для проведения вторичной экспертизы могут являться сомнения суда в компетентности эксперта, составившего заключение, а также возникновение разногласий в выводах экспертного решения. В отличие от дополнительной экспертизы вторичная проводится в полном объеме.

В основном экспертиза выполняется одним специалистом, который обладает необходимыми компетенциями в определенной области. Несмотря на это, иногда на выполнение экспертных работ могут быть назначены несколько экспертов. Это требуется в том случае, когда необходимо исследовать большой объем материалов в разных областях сфер деятельности или науки.

Рассмотрим разновидности экспертиз по правовому статусу. В Федеральном законе № 73 «О государственной экспертной деятельности в Российской Федерации» описаны основные права и обязанности судебных экспертов. Согласно данному нормативу «экспертиза» определяется как «процессуальное действие, состоящее в проведении исследования и даче экспертного заключения по вопросам, которые ставятся перед экспертом судом в целях установления обстоятельств, подлежащих доказыванию по конкретному делу» [2].

Согласно Арбитражному и Гражданскому процессуальным кодексам Российской Федерации, при рассмотрении дела суд вправе назна- 
чить экспертизу в целях разрешения вопросов, требующих специальных знаний в различных областях науки. В случае, когда судебная экспертиза назначается в организациях, которые занимаются государственной экспертизой, не возникает никаких сложностей с нормативным регулированием, поскольку данный вид деятельности установлен на уровне законодательства.

Кроме того, в ходе проведения экспертизы в муниципальных экспертных учреждениях реализуются принципы независимости экспертов, объективности и полноты объема исследований. Работа экспертов в этих организациях регулируется договором или контрактом, а вознаграждение является повременным, то есть не зависит от объема выполненных экспертиз. Это означает, что независимость эксперта сохраняется.

На данный момент определение понятия «строительная экспертиза» в нормативной базе не существует. Несмотря на это, данный термин описывает независимую экспертизу для определения стоимости работ, исследование строительных конструкций, зданий, сооружений, их текущего состояния и несущей способности.

В свою очередь, строительная экспертиза имеет свои разновидности. На территории России в зависимости от органа, являющегося инициатором проведения строительной экспертизы, она имеет следующие виды:

- судебная;

- несудебная.

Каждый из этих видов экспертиз выполняется по трем ключевым направлениям:

- обследование недвижимых объектов,

- технический надзор,

- оценка недвижимости.

Из-за сложности проведения и большого количества задействованных лиц судебная строительная экспертиза является одним из самых сложных видов экспертиз. В ее основе лежат научные исследования, наблюдения и привлечение опытных высококвалифицированных специалистов в различных отраслях.

Судебная экспертиза предполагает процессуальные действия, проведение исследований и составление заключения экспертом по вопросам, составленным судом, прокурором или другими должностными лицами, для того чтобы установить достоверную картину по данному делу [3].

Судебная строительная экспертиза как разновидность инженерно-технических эксперт- ных работ имеет важно значение при решении следующих задач:

- в процессе решения разногласий о праве собственности на недвижимое имущество;

- при решении споров между заказчиком и исполнителем;

- в ходе определения видов выполняемых работ, их объема, качества и стоимости в зданиях на стадиях строительства или эксплуатации;

- в процессе рассмотрения дел об административных правонарушениях, в которых необходимо наличие доказательств обоснованности строительства или эксплуатации зданий и сооружений;

- в процессе определения причины и размера материального ущерба, причиненного жилым зданиям, строениям и помещениям, в результате некачественно произведенных работ в процессе строительства или эксплуатации различных инженерных систем;

- в процессе изучения уголовных дел о несчастных случаях, авариях и других происшествиях в строительстве;

- в ходе установления соответствия экспертных работ требованиям стандартов, регламентирующих процессы проектирования, строительства, эксплуатации, ремонта и демонтажа объектов строительства [4].

Несудебная экспертиза не предполагает процессуальных действий, она может быть проведена по заявлению физического или юридического лица. На сегодняшний день данный вид экспертизы очень популярен и широко используется. [5]

Строительная несудебная экспертиза имеет свои разновидности по предмету исследования и по субъекту, который занимается её осуществлением:

- государственная;

- негосударственная.

Независимая строительная экспертиза характеризуется высоким качеством и надежностью в отношении оценки строительного объекта. Она позволяет получить подробную информацию о строящемся здании или сооружении.

В основу данного вида экспертизы входят анализ и сравнение проектной, нормативной и правовой документаций. Результатом проведения данной экспертной работы случит документальное заключение.

В экспертном заключении отражены все вы- 
явленные нарушения с приложением всех доказательств в виде фотографий, ссылок на нормативную документацию в соответствии с которой были определенны допустимые отклонения.

Строительная экспертиза применима в случаях:

- при желании провести работы по реконструкции здания или выполнить капитальный ремонт;

- в следствие причинения ущерба имуществу посторонними лицами или при пожаре и различных природных катаклизмах;

- при потребности оценки стоимости выполненных подрядчиком работ;

- с целью оценки состояния износа несущих и ограждающих конструкций и здания в целом в процессе эксплуатации.

Помощь независимой экспертизы строительства необходима в случае партнерских отношений с финансовыми организациями, когда требуется получить кредит на возобновление финансирования и на развитие проекта.

Далее мы рассмотрим проблемы, возникающие в области судебно-строительной экспертизы.

В соответствии с нормативной документацией судебным экспертом может быть представитель государственной экспертной организации или любое другое лицо, обладающее необходимыми для этой деятельности компетенциями. Несмотря на это, особых требований к негосударственным экспертам и экспертным организациям нет.

Такая ситуация способствовала тому, что любое физическое или юридическое лицо может осуществлять экспертную деятельность. На сегодняшний день профессиональное сообщество экспертов внесло предложения по совершенствованию законодательства в этой сфере. Они заключаются в создании единых требований к экспертам и экспертным организациям, как государственным, так и негосударственным.

Стоит также обратить внимание на то, что в России суды не имеют деления на профили. Это приводит к трудностям в процессе установления правоты одной из сторон дела, так как суд не обладает специальными знаниями и опытом работы в строительной отрасли.

Летом 2020 года ассоциацией экспертиз строительных проектов (далее АЭСП) состоялось совещание с учреждениями государственной экспертизы регионов по насущным вопросам в области экспертных органов субъектов РФ.АЭСП были выделены следующие проблемы [6]:

1. Отсутствие нормативной базы, которая регулирует нормы по оформлению заключений экспертиз. На данный момент еще не принят нормативный документ, в котором будут включены изменения Градостроительного кодекса. На данный момент есть только указания Министерства строительства о том, что есть возможность использовать произвольную форму заключения, а также в процессе подготовки экспертного заключения необходимо использовать проект приказа Министерства строительства РФ, который находиться на сайте проектов нормативных документов.

2. Существуют сложности в правильности применения территориальных сметных нормативных документов в отношении их индексации. В некоторых регионах России бывали случаи возбуждения уголовных дел по фактам применения данных нормативов. Учитывая существующие объяснения Министерства строительства РФ и Главгосэкспертизы, АЭСП сделала следующие выводы: региональные сметные нормативные документы могут использоваться для определения сметной стоимости строительства, кроме того, есть возможность их индексации субъектами РФ.

На данный момент нормативно-правовая база в этом направлении продолжает развиваться. Было принято методическое руководство по определению сметной стоимости строительства. Однако, пока что эта информация нигде не освещена по причине того, что на данный момент еще не пройдена регистрация в Министерстве юстиций РФ. После того, как этот документ будет официально опубликован тема нормативного регулирования смет возникнет снова.

3. Необходимость подробного описания процедур, связанных с заданием на проектирование. Согласно приказу Минстроя России от 10 июня 2020 года № 313/пр были приняты «Методические рекомендации о проектах заданий на архитектурно-строительное проектирование объектов капитального строительства, строительство (реконструкция) которых осуществляется за счет средств бюджетов бюджетной системы Российской Федерации».

В данном документе содержится множество не до конца проработанных мер. В большей части субъектов России выявлены ситуации, когда заказчики не могут выдать полный комплект 
документов, который обосновывает проектирование. Организации, являющиеся основными управленцами бюджетных средств, и выступающие заказчиком экспертных работ, не имеют возможности подготовить и предоставить полный комплект документов. Необходима доработка относительно требований к организациям и учреждениям, которые будут ответственны за выполнение этой работы. Решением данной проблемы может являться разделение проверки достоверности и технической части между исполнителями.

4. Требуются четкие указания в процесс экспертного сопровождения проекта. Госэксертиза в рамках экспертного сопровождения по-прежнему имеет ряд нерешенных вопросов. Существует потребность в четкой классификации экспертиз в нормативных документах, а именно: описание случаев в который следует проводить экспертное сопровождение и повторную экспертизу. Кроме этого, необходима разработка методологии экспертного сопровождения, описание прав и обязанностей организации, которая занимается разработкой проекта, а также детализация процесса экспертного сопровождения.

5. Решение вопроса аттестации экспертов. у большей части управляющих экспертных организаций в регионах нашей страны нет четкого понимания в каком формате будет проводится аттестация экспертов для осуществления гос. экспертизы. Ранее Министерством строительства РФ было объявлено о продлении еще на год срока действия аттестатов для некоторых экспертов. Стоит отметить, что вопрос в какой форме будет проходить аттестация для других специалистов на данный момент остается нерешенным.

На сегодняшний день по-прежнему не ясны ограничения для аттестации экспертов, имеющих возможности аттестовать специалистов, которые завершили обучение в специализированных центрах переподготовки. Кроме этого, пояснений требует методика организации очного и онлайн-тестирования и процесса проведения экзаменов для экспертов.

Данная проблема является одной из устаревших, для решения которой требуется системный подход. Она создает ограничения для полноценного функционирования экспертной деятельности.

Подводя итог, можно сделать вывод о том, что сфера строительства в Российской Федерации развивается с каждым годом, доказательством является динамика роста ввода жилых домов. Однако, в некоторых направлениях строительства существует ряд недоработок в нормативно-правовом регулировании, в число областей, требующих внимания, входит экспертное направление. Нами были выделены следующие проблемы строительной экспертизы:

1) отсутствие четких требований к эксперту в области проведения судебной строительной экспертизы;

2) отсутствие нормативной базы, которая регулирует нормы по оформлению заключений экспертиз;

3) требует уточнений применение территориальных сметных нормативных документов;

4) необходимость уточнения процедур, относящихся к составлению задания на проектирование;

5) решение вопроса аттестации экспертов.

Подытожив, можно сделать заключение о том, что экспертизу строительства в Российской Федерации в ближайшее время ждет ряд нормативно-правовых поправок, что неизбежно отразиться на качестве выполнения экспертных исследований, а также на взаимоотношениях субъектов строительства в лице заказчика и подрядчика и на общем качестве работ по строительству в нашей стране.

\section{Библиографический список}

1. Федеральная служба государственной статистики. Официальные данные. Движение жилищного фонда [Электронный ресурс] URL: https://rosstat.gov.ru/folder/14458 (Дата обращения 20.10.2020).

2. Федеральный закон от 31 мая 2001 г. № 73 ФЗ «О государственной экспертной деятельности в Российской Федерации» (с изменениями на 26 июля 2019 года) [Электронный ресурc] URL: http://docs.cntd.ru/ document/901788626 (Дата обращения 20.10.2020).

3. Мирончук Н. С. Судебно-строительная экспертиза в России и ее современные особенности // E-SCIO. 2019. № 6. С. 520-527.

4. Россинская, Е. Р., Галящина, Е. И. Настольная книга судьи: судебная экспертиза.- М.: Проспект, 2010.-464 с. 
5. Дьяконова, О.Г. Процессуальная регламентация несудебной экспертизы / О.Г.Дьяконова // Эксперткриминалист. - 2010.- № 2.

6. Состоялось видеоселекторное совещание членов АЭСП [Электронный ресурc] URL: http://www.aexpertiz.ru/ press/expnews/SostoyalosvideoselektornoesoveshchaniechlenovAESP/ (Дата обращения 20.10.2020). 